\title{
Potential of a lactobacilli probiotic to counteract the toxic effects of Fusarium mycotoxins
}

\author{
I. Taranu ${ }^{1}$, D. E. Marin ${ }^{1}$, G. Manda $^{2}$, M. Burghelea ${ }^{1}$ and C. Tabuc ${ }^{1}$ \\ ${ }^{1}$ Institute of Biology and Animal Nutrition, Balotesti, Romania and ${ }^{2}$ Institute V. Babes, Bucharest, Romania
}

Mycotoxins are secondary toxic metabolites produced by several fungi, natural contaminants of feed and food. Their global occurrence is considered an important risk factor for human and animal health. Deoxynivalenol (DON) is a mycotoxin produced by Fusarium sp. known to provoke feed refusal and slow growth in domestic animals as well as an impaired immunity functions at low concentrations. Pigs have been identified as the most sensitive animal species regarding these adverse effects. However, at present few studies of the effects of DON on pig immune response are available.

The potential of a probiotic product (a mixed culture of Lactobacillus sp. and Enteroccous faecium on feed meal support) to counteract the immunotoxic effects of DON in pig was assessed in an in vivo study. A total mixed feedstuffs naturally contaminated with Fusarium mycotoxins in which DON was the major contaminant $(1.4 \mathrm{mg} / \mathrm{kg})$ was fed for 24 days to 16 weaned piglets randomly assigned to one of the four treatments: (1) control group, (2) contaminated group, (3) probiotic group (50 g/pig/ds) and (4) contaminated plus probiotic group; they were assessed for performance, serum biochemistry and some of innate and acquired immune response. Feed intake, body weight and part of the serum biochemistry were slightly affected by the contaminated diet (i.e. $18.2 \%$ of body weight decrease $v$. control), but the toxic effect was alleviated by the dietary probiotic supplementation. At the innate immune level, DON significantly increased the reactive oxygen species (ROS) production in blood and pro-inflammatory cytokines (IL-8 and TNF- $\alpha$ ) synthesis in liver. Similarly, the respiratory burst of porcine-activated blood phagocytic cells increased significantly as a consequence of DON toxic capacity from 22.6 to $70.9 \%$. This effect was disrupted by the probiotic dietary supplements. Pigs fed the contaminated diet also presented significant alterations of their humoral and cellular immune response. A significant increase in the ex vivo unstimulated or mitogen-stimulated peripheral mononuclear blood cells proliferation and in the level of $\mathrm{CD}^{+}$and $\mathrm{CD}^{+}$lymphocytes populations was also observed. Total plasma immunoglobulins (IgA, IgG and IgM) derived from intoxicated animals were higher than those of the control. The intake of the probiotic had a notable positive effect on these antibodies subsets; an increase of $44.5 \%$ in IgM concentration and $49.2 \%$ in IgG concentration was observed in piglets receiving the probiotic. Level of cytotoxic T-cells $\left(\mathrm{CD}^{+}\right)$in the blood of piglets of the probiotic group was also highly increased.

Our study demonstrates that low doses of DON depress pig performance and alter many aspects of innate and acquired immunity in pigs (Table 1). The dietary probiotic supplement counteracted totally or partially the negative effects of DON.

Table. 1. Effect of DON and probiotic supplement on immune response

\begin{tabular}{|c|c|c|c|c|}
\hline & \multicolumn{4}{|c|}{ DON (ppm) and probiotic (g) concentration } \\
\hline & Control $(0)$ & Probiotic (50) & DON (1.4) & $\mathrm{DON}+$ probiotic $(50+1.4)$ \\
\hline $\begin{array}{l}\text { Innate immune response } \\
\text { Cell respiratory burst (\%) } \\
\text { Plasma ROS (A } 405 \mathrm{~nm})\end{array}$ & $\begin{array}{l}22.6 \pm 0.2 \\
0.06 \pm 0.04\end{array}$ & $\begin{aligned} 24.1 & \pm 6.64 \\
0.024 & \pm 0.0\end{aligned}$ & $\begin{array}{l}70.9 \pm 2.0 \\
0.30 \pm 0.05\end{array}$ & $\begin{array}{l}36.3 \pm 8.0 \\
0.07 \pm 0.04\end{array}$ \\
\hline $\begin{array}{l}\text { Humoral response } \\
\text { Plasma IgA }(\mathrm{mg}) \\
\text { Plasma IgM }(\mathrm{mg}) \\
\text { Plasma IgG }(\mathrm{mg})\end{array}$ & $\begin{array}{r}1.36 \pm 0.6 \\
2.05^{\mathrm{b}} \pm 0.4 \\
6.36^{\mathrm{b}} \pm 0.8\end{array}$ & $\begin{array}{r}1.26 \pm 0.5 \\
2.97^{\mathrm{a}} \pm 0.5 \\
9.49^{\mathrm{a}} \pm 0.5\end{array}$ & $\begin{array}{r}1.42 \pm 0.8 \\
2.43^{\mathrm{a}} \pm 0.8 \\
7.81^{\mathrm{b}} \pm 0.6\end{array}$ & $\begin{array}{r}1.09 \pm 0.4 \\
2.63^{\mathrm{a}} \pm 0.4 \\
10.79^{\mathrm{a}} \pm 6.2\end{array}$ \\
\hline $\begin{array}{l}\text { Cellular response } \\
\text { Stimulated cell proliferation }(\mathrm{cpm})\end{array}$ & $107975 \pm 2430$ & $103710 \pm 8504$ & $111801 \pm 2683$ & $101550 \pm 3623$ \\
\hline
\end{tabular}

${ }^{\mathrm{a}, \mathrm{b}}$ Mean values within rows with unlike superscript letters were significantly different. 